Vol. XVII No. 1

\title{
Nature Photography
}

\section{By Hans Dommasch, University of Saskatchewan, Saskatoon}

Nature offers a world of unique beauty free to every living being. To discover and marvel at all this you need neither wealth nor possession, only simple insight and understanding. To anyone interested in nature, nature photography is an exciting hobby. If you know how, you may with your camera bring home evidence of all the wonders of nature which you may share with others. Your appealing shots of animal's can help the cause of conservation and your hobby can be of asisistance to scientists and biologists.

Shooting with a camera can bring you as many thrills as actual hunting but it requires much more skill, patience and knowledge. A grod rifle shot can bring down game even at a distance, whereas at the same distance it would be impossible to get a picture at all. The wildlife photographer has to know the habits of hiis subjects. He musit be ab!e to judge distance. He must learn many tricks in handling his light-sensitive equipment. Experience and careful observations are necessary b£fore one can become a good wildlife photographer.

Last summer I decided to try to take a phctograph of a beaver. Before I was ready to make my first attempt I spent two eveningis down by the beaver lodge clbiserving the hiabits and behaviour of the beaver family. How could I trick the beaver into posing for my picture? Unfortunately the photograph could only be taken at night which made estimating the distance and focusing difficulit. After careful observation I selected a spot where a beaver should come, sooner or later, on his way to the woods. I decided to cut down a small tree and plant it right in the path which I hoped the beaver would take. The camera was set up on a tripod, along with two flash lights. Five hours later the photograph, shown below, was obtained. During the waiting period I watched the beavers both at work and at play, thus learning mare about the animals I was photographing.

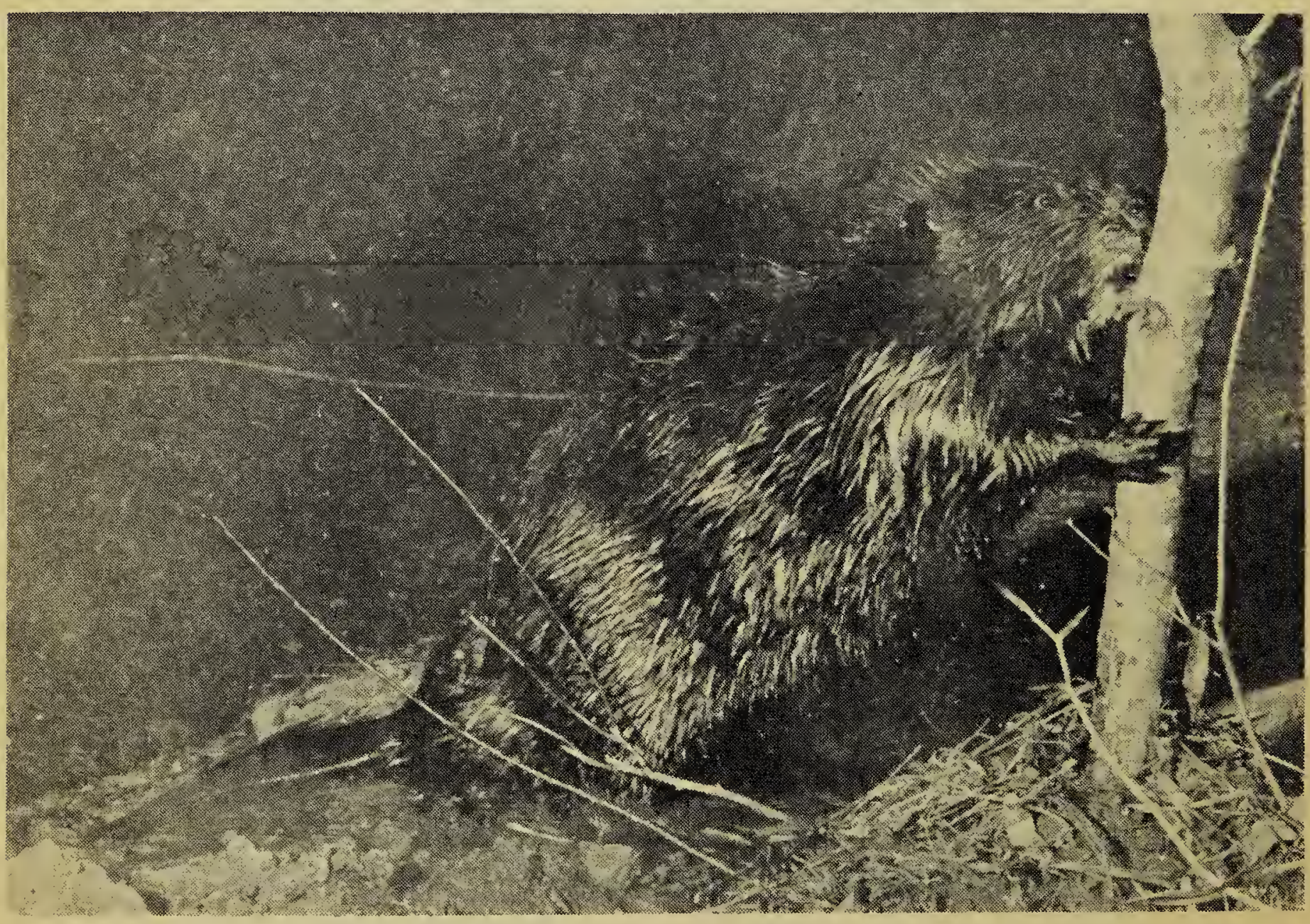

Photo by H. Dommasch BEAVER, photographed at night using fast panchromatic film and two number 22 flashbulbs. 


\section{SUBJECT}

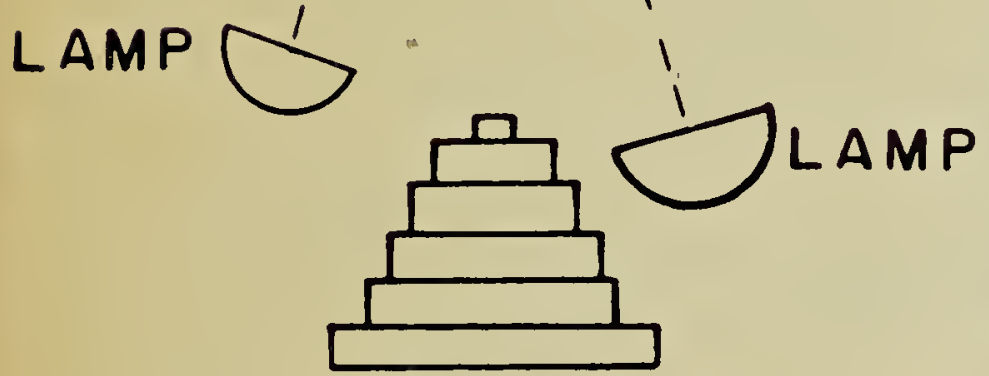

CAMF.RA

Set-up for taking the beaver photo at night with fast panchromatic film and two No. 22 flashbulbs.

\section{FIRST RULES IN NATURE PHOTOGRAPHY}

Here are a few rules to ensure better results and to make your new hobby of nature photography more enjoyable.

1. Patience! Patience!

2. The photographer's first concern should be for the animals' welfare, not for the obtaining of a photograph regardless of the cost.

3. Much attention should be given to placing your camera or blind. It may take two or three days to move the blind close enough to the subject.

4. If taking pictures at a nest the blind or camera should be moved only when the bird is away from the nest. The camera should be higher than the rim of the nest.

5 . Focus accurately and stop down the lens as much as the light conditions will allow to obtain the maximum depth of field.

6 . If you intend to take pictures from a hide (blind) you should have an assistant. When the assistant walks away the animals (especially birds) seem to think that the hide is empty.

7. Patience! Patience! Patiénce!
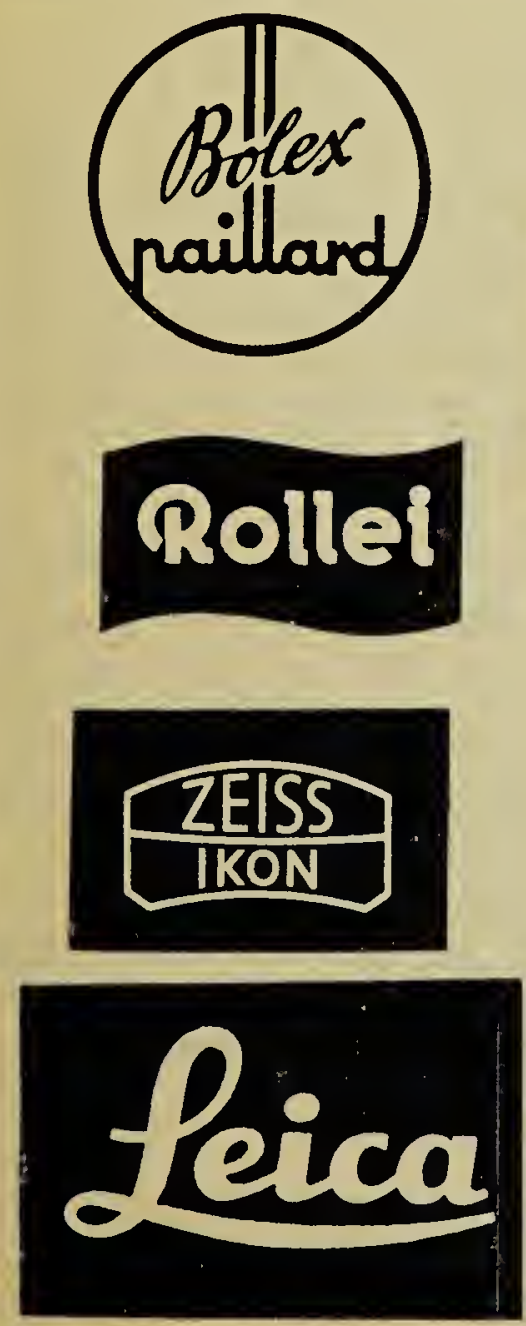

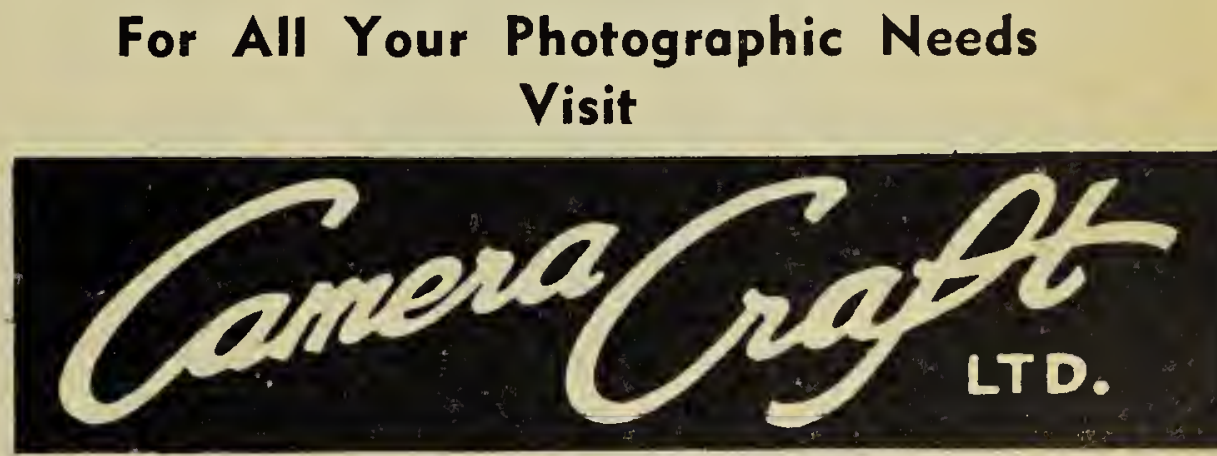

"THE PHOTOGRAPHIC CENTER"

Temporary Location:

11 th AVENUE and SMITH STREET REGINA, SASK. 幽完

\section{SOON a Brand New Store} to serve you better.

Enquiries about your photographic needs will be answered with pleasure and without charge. 